\title{
Gravimetric Studies in the Sea of Japan
}

\author{
Maksim Georgievich Valitov, Ruslan Grigoryevich Kulinich, \\ Zoya Nikolaevna Proshkina, and Tatyana Nikolaevna Kolpashchikova
}

\section{Abstract}

Marine gravimetric studies were carry out in the waters of the Sea of Japan and the Tatar Strait. Maps of the gravitational field of the earth were completed, structural density modeling was executed, the depth of the Mohorovičić discontinuity was determined.

\section{Keywords}

Earth's crust - Marine gravimetric studies - Mohorovičić discontinuity · Sea of Japan · Structural density modeling

\section{Introduction}

The Sea of Japan, washing the southeastern coast of Russia, cuts almost across the cut the southern tip of the SikhoteAlin and Laoelin-Grodekov fold systems. Here, at a short distance, a radical restructuring of the earth's crust takes place: the transition from a mature continent to a young oceanic crust with the disappearance or significant processing of the upper sialic shell rich in ore and non-metallic minerals. According to modern concepts, this, like the formation of the Sea of Japan as a whole, is the result of Meso-Cenozoic destruction of the margin of the Asian continent and rifting, which was replaced by spreading with the formation of a young oceanic crust in the eastern part of the deepsea Japanese Sea basin. As a result, a region was formed within which two radically different types of the earth's crust closely "coexist".

The deep structure of the earth's crust of this region is still an actual object of study. The decisive role in this is assigned to geophysical methods, in particular, seismic sounding and gravimetry. The capabilities of gravimetry to study the problem under consideration are based on the fact that one of

M.G. Valitov $(\bowtie) \cdot$ R.G. Kulinich · Z.N. Proshkina · T.N. Kolpashchikova

V.I. Il'ichev Pacific Oceanological Institute Far Eastern Branch Russian Academy of Science, Vladivostok, Russia

e-mail: valitov@poi.dvo.ru the parameters distinguishing the continental crust from the oceanic crust is their significantly different thickness (the depth of the Mohorovičić discontinuity or Moho (M)). This parameter with acceptable reliability is determined using gravimetry in combination with the reference data of seismic sensing, which makes it possible to determine the relief of the base of the earth's crust in a given area. On the other hand, with a "fixed" structural framework, density modeling of the geological environment is possible, which makes it possible to study changes in the material composition of the crust masses. The combination of both situations makes it possible to realize structural-density (structural-material) modeling and, thus, to study the deep structure of the earth's crust at the junction of its heterogeneous types.

\section{$2 \quad$ Marine Gravimetric Studies}

The first measurements of gravity in the Sea of Japan were made by Soviet researchers in 1937. Professor of Moscow State University L.V. Sorokin in a submarine made measurements of gravity at 74 points (Stroev et al. 2007).

Until the mid-1980s of the last century, the main contribution to the study of the anomalous gravitational field of the Sea of Japan was made by the P.K. Sternberg's State Astronomical Institute, who is part of Moscow State University (GAISH Moscow State University), in particular, his staff V.L. Panteleev, A.D. Gainanov, P.A. Stroyev and others. Unfortunately, the measurements were performed on 
disconnected polygons and profiles. Profile measurements were taken over the Pervenets Rise, over the southern part of the Bogorov Ridge, detailed areal observations within the Yamato Rise, at three polygons: near the Korea peninsula, and near the mainland slope of northern Primorye (Belousov et al. 1973; Stroev and Kovylin 1973).

At the same time, the entire eastern half of the Sea of Japan was covered by gravimetric surveys by the Hydrographic Service of the Ministry of Defense of Japan and Japanese universities (Tomoda 1973; Tomoda and Fujimoto 1981).

Since the mid-1980s, the V.I. Il'ichev Pacific Oceanological Institute Far Eastern Branch Russian Academy of Science (POI FEB RAS) has concentrated geophysical work in the northwestern part of the Sea of Japan (Fig. 1), within the economic zone of the Russia (formerly USSR). In addition to onboard gravimetry, seismic profiling and magnetometry were included in the set of these works (Prokudin et al. 2018)

The first measurements of gravity at this stage (19871989), simultaneously with continuous seismic profiling (NSP) and hydro-magnetic surveying, were performed using on-board gravimeters GAG-ZhZ and GMN-K with analog recording of recordings on recorders. At that time, the navigational reference was very weak, positioning in the open sea was carried out no more than once in $4 \mathrm{~h}$, in coastal areas, data from coastal radio navigation stations were used. The coordinates of the observation points were calculated by interpolation and navigational calculations, location errors introduced serious errors in the final accuracy of the survey. The measurement error was $\pm(2.4-3.0 \mathrm{mGal})$.

In 1990 (the 6th cruise of the R/V "Professor Gagarinsky"), survey was carried out on the border of the economic zones of Russia and North Korea, as well as on the Yamato
Fig. 1 Scheme of the gravimetric study of the Sea of Japan. OP54-54 cruise R/V

"Academician Oparin", LV81-81 cruise R/V "Academician M. Lavrentiev”, OP55-55 cruise R/V Academician Oparin, LV85-85 cruise R/V "Academic M. Lavrentiev", GA - cruises made on vessels of the Far Eastern Branch of the Russian Academy of Sciences in the period from 1982 to 2010

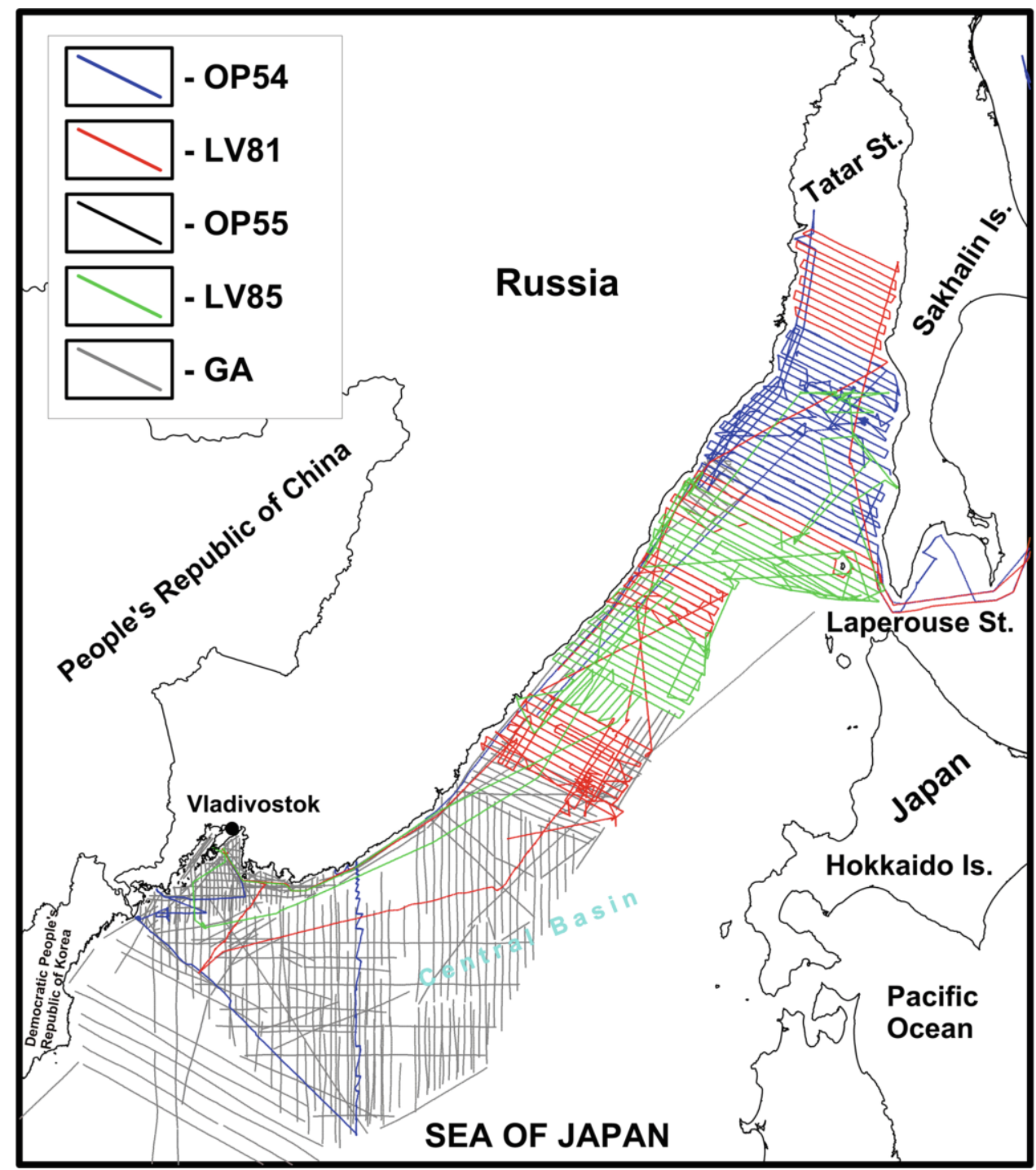


Rise. The survey was carried out by six GMN-K instruments with analog registration (error $\pm 2.4 \mathrm{mGal}$ ). The direction of the profiles is meridional on the Yamato Rise and northwest in the coastal part of the Sea of Japan, the distance between the profiles is 10 miles.

The survey was continued in 1991 and 1994 in the Central basin of the Sea of Japan (cruise No. 11 and 14 of the R/V "Professor Gagarinsky"). The observations were carried out by five GMN-K instruments with analog and then with digital recording. The error of observations in 1991 was $\pm 2.1 \mathrm{mGal}$, and in $1994 \pm 1.6 \mathrm{mGal}$. The direction of the profiles is meridional, the distance between the profiles on the 11 th cruise was 10 miles, and on the 14 th cruise -5 miles. Characteristically, since 1994, GPS receivers began to be used for navigational support for marine surveys of the POI FEB RAS, which significantly increased the accuracy of the survey.

The Pervenets Rise is studied in detail in the 18th cruise of the R/V "Professor Gagarinsky" (1996). The survey was carried out by six GMN-K instruments with digital recording (error $\pm 1.4 \mathrm{mGal}$ ). The direction of the profiles is northeast, the distance between the profiles is 5 miles.

In 1996 (the 27th cruise of the R/V "Akademik M.A. Lavrentyev"), a single profile survey was taken of the northern end of the Central Basin and the Bogorov Ridge. The survey was carried out by six GMN-K instruments with digital recording (error $\pm 1.4 \mathrm{mGal}$ ).

The study of the northern part of the Central Basin continued on the 21st cruise of the R/V "Professor Gagarinsky" (1997). The survey was carried out by five GMN-K instruments with digital registration (error $\pm 2.0 \mathrm{mGal}$ ). The direction of the profiles is northwest, the distance between the profiles is 5 miles.

In 1998, at the R/V "Professor Gagarinsky" (24th cruise), a regional gravimetric survey was carried out in the Central Basin using a series of meridional and latitudinal profiles. The distance between the profiles was $25 \mathrm{~km}$. The observation error was $\pm 1.6 \mathrm{mGal}$.

In 2003, POI FEB RAS (cruise 36) of the R/V Professor Gagarinsky carried out a detailed geophysical (including gravimetric) survey of Peter the Great Bay. The average distance between the profiles did not exceed $2 \mathrm{~km}$. The observation error was $\pm 1.4 \mathrm{mGal}$. The location of the observations was determined using GPS satellite system.

In 2010, the R/V "Akademik M.A. Lavrentyev" (cruise 52 ) of the POI FEB RAS carried out a gravimetric survey $( \pm 2.0 \mathrm{mGal}$ error) at the northern closing of the Central Basin, in the vicinity of the Vityaz Rise.

This completed the first stage of areal geophysical work in the Central Basin of the Sea of Japan, within the economic zone of the Russian Federation. The root-mean-square error, calculated from the intersection of various gravimetric surveys, did not exceed $5 \mathrm{mGal}$. Measurement processing was carried out according to standard methods. At the first stage, straight sections of the profiles were chosen, them the vessel moved with uniform speed and constant heading. The Eötvös correction, correction for the cross-dropping effect, for the inertia of the measuring systems of gravimeters, and zero drift were introduced. From the observed values, the normal gravitational field of the Earth, calculated according to the international formula of 1967, was subtracted. The anomalous field thus obtained was analyzed for intersections, after which gravimetric data catalogs were created. The construction of maps was carried out in the SURFER Golden Software program. The main operation at the initial stage of mapping was the creation of a regular grid of gravitational field values with a square cell (grid) based on an irregular pseudo-rectangular grid of observed data. When building the grid in the specified program, the so-called "search radius" was used, i.e. the distance within which data is searched to interpolate a regular grid value. In our calculations, the optimal search radius was set from 5 to $25 \mathrm{~km}$ depending on the degree of exploration of the water area, as a result of which three nearby profiles participated in the formation of the interpolation value of gravity at each grid node. The map constructed in this way is shown in Fig. 2a.

Starting from 2017, the POI FEB RAS, at a new qualitative level, resumed geophysical exploration of the Sea of Japan. Marine gravimetric survey was carried out with Chekan-AM mobile gravimeters (Shelf-E modification) serial number 47. Studies were concentrated in the northern part of the Sea of Japan: the closure area of the deep-water Central Basin and the Tatar Strait. To date (October 2019), four expeditions have already been carried out in this area under the project "Integrated geological-geophysical, gasgeochemical and oceanographic studies in the Sea of Japan and the Tatar Strait."

So in 2017 at the R/V “Akademik Oparin" a geophysical survey was carried out in the southern part of the Tatar Strait from the latitude of the port of Sovetskaya Gavan in the north to the latitude of about. Moneron in the south. 112 geophysical profiles with a total length of 3,860 miles were completed here. The survey error did not exceed $\pm 0.49 \mathrm{mGal}$.

In 2018, two expeditions were completed. The research of the first expedition, to the R/V "Akademik M.A. Lavrentyev", was concentrated in the junction zone of the Central Basin of the Sea of Japan with the Tatar Strait trough valley. The second, at the R/V "Akademik Oparin", passed north, from the latitude of the Soviet harbor to Cape Surkum. The survey error, in the first case, did not exceed $\pm 0.38 \mathrm{mGal}$, in the second $\pm 0.4 \mathrm{mGal}$.

In May-June 2019, expeditionary studies were carried out in the remaining, not studied by us, part of the Tatar Strait, south of Moneron Island. During the expedition more than 113 tacks were completed, with a total length of more than $6,170 \mathrm{~km}$. The survey error did not exceed $\pm 0.38 \mathrm{mGal}$. 
Fig. 2 Map of gravitational anomalies in free air (conditional level), made according to ship on-board measurements for the period of expeditionary research from 1982 to 2010 (a) and from 2017 to 2019 (b). The numbers indicate: 1 - Peter the Great Seamount; 2 - Bogorov Ridge; Rises: 3 - Pervenets, 4 - Vityaz, 5 - Yamato, 6 - Alpatov, 7 Lavrentiev a)

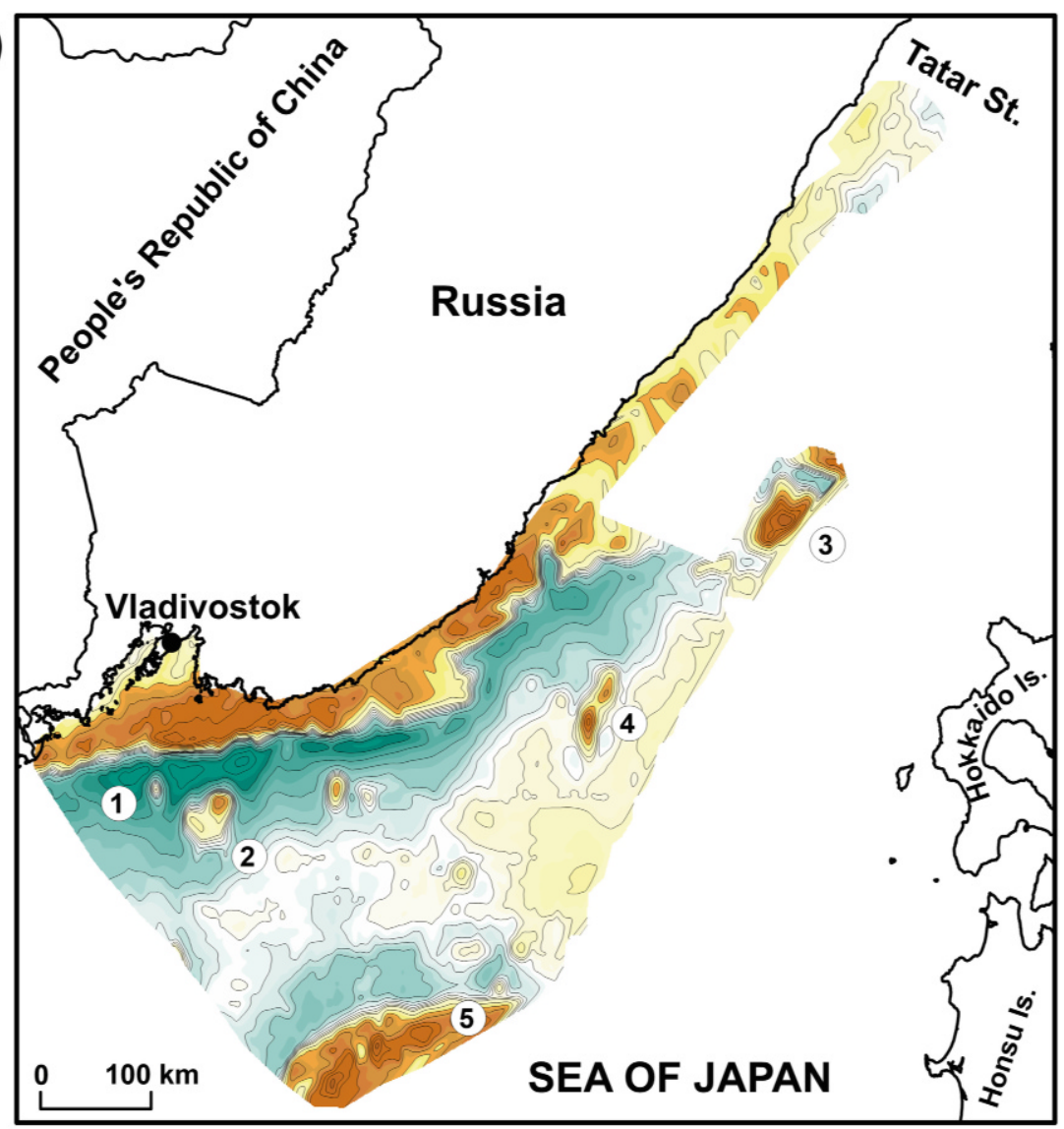

$\Delta \mathbf{g}, \mathrm{mGal}$
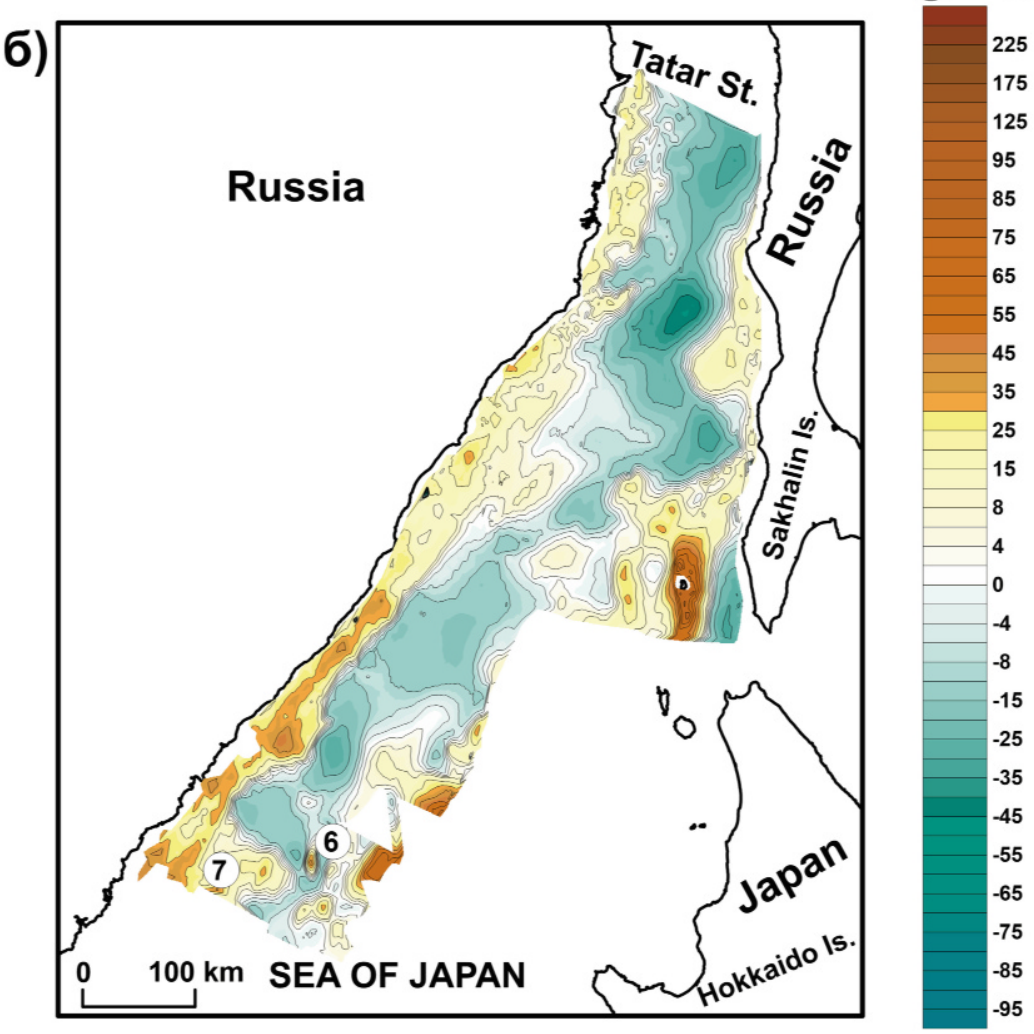


\section{$3 \quad$ Results}

The works listed above made it possible to close white spots in the scientific geophysical study of the entire northwestern part of the Sea of Japan adjacent to the continent (Primorye, northern part of the Korea Peninsula). In recent years, the area of articulation of the Tatar Strait with the northern closure of the Sea of Japan and most of the Tatar Strait itself has been studied. This allowed, firstly, to build a series of conditional geophysical maps on a scale of 1:1,000,000 (including gravimetric) and, secondly, to study the structural and genetic relationship of the Central Japanese basin with the margins of the adjacent continent. One of the directions of such studies was the gravitational (density) modeling of the earth's crust at the junction of the indicated basin with the shelf and coastal geological structures of southern and south-western Primorye.

Modeling is one of the effective methods for studying the deep structure, physical properties and processes occurring in the bowels of the tectonosphere, based on the use of available data and ideas about the environment. The authors, in particular, in the framework of these studies quite widely used the so-called gravitational (density, structural-density) modeling. A gravitational model is usually understood as a density model, the calculated gravitational field from which, up to a constant component, is adequate to the initial field of gravity (Bryansky 1991). "By calculating models of the density distribution in the geological environment that create an effect similar to the observed gravitational field, we can obtain information about the structure of the geological environment" (Krasovsky 1981).

Structural-density modeling (Fig. 3) was carried out according to a series of profiles crossing the transition zone from the edge of the continent to the central deepsea basin of the Sea of Japan, which quite clearly showed the characteristic features of the transformation of the continental crust into the oceanic crust.

Transformation of the crust begins on the continent at a considerable distance from the upper edge of the continental slope. In different sections, this distance is not the same.

The transformation of the continental crust is both structural and substantial nature. The main factor determining this transformation is the reduction in the thickness of the "basalt" layer from the continent towards the basin of the Sea of Japan and its replacement with a mantle substrate. The supra-basaltic crust (crystalline basement) in most cases practically does not change its thickness to the continental slope. However, the substantial composition of this foundation in different parts of the studied area does not remain the same.

The final transformation of the continental crust occurs within a narrow strip of the outer shelf - the bottom of the continental slope. Here its sialic part disappears com- pletely, the thickness of the lower crust ("basalt" substrate) is significantly reduced, which is replaced by mantle masses from below. In all the sections presented in the slope part, an increase in the thickness of the "transition" layer is observed, which indicates the processes of effusion of effusive rocks that took place here, with the formation, in some cases, clearly expressed in the relief of volcanic structures (Seamount Peter the Great).

At the base of the slope and the slope of the deep-sea basin, a narrow zone of deformations of all layers of the oceanic crust is recorded on all profiles, which can be a morphological expression of a powerful tectonic structure (tectonic seam) at the junction of dissimilar types of the earth's crust.

Another area of research was the depth's determination of the Mohorovičić discontinuity (Moho surface) bedding within the Sea of Japan. It is well known that on the Mohorovičić discontinuity there is a sharp increase in the speed of seismic waves and, accordingly, the density of the underlying rocks. Similar changes in density are observed during the transition from the water column to the upper part of the sedimentary layer and during the transition from the lower part of the sedimentary layer to consolidated rocks of the underlying layers (acoustic foundation). The observed gravitational field reflects the integral effect of the above boundaries and can be used to determine the depth of their occurrence by statistical methods. To determine the depth of the Mohorovičić discontinuity within the study area, we used the statistical dependence of the magnitude of the averaged gravitational anomalies, sedimentary cover thickness and sea depth on the depth of the Mohorovičić discontinuity, proposed in (Su Datsuan 1982):

$$
H=33.49-0.063 \Delta g_{\text {free }}-0.00482 H_{\text {sea }}-0.0017 h_{\text {sed }}
$$

where $\mathrm{H}$ is the depth to the Mohorovičić discontinuity, km; $\Delta g_{\text {free }}$ - anomaly in free air, $\mathrm{mGal} ; H_{\text {sea }}$ - depth of the seabed, $\mathrm{m} ; h_{\text {sed }}-$ thickness of the sedimentary layer, $\mathrm{m}$. The depths of the seabed $\left(H_{\text {sea }}\right)$ were determined according to the sonar data, $h_{\text {sed }}$ were determined according on the NSP data.

As is known, there is a statistical relationship between the thickness (the depth of Mohorovičić discontinuity) and the type of the earth's crust (Belousov and Pavlenkova 1985). Moho depths in the indicated area are shown in the Figure 4. As can be seen from the figure, the relief of the base of the crust of the Central Basin of the Sea of Japan and its neast framing is of considerable complexity, which indicates the heterogeneity of different parts of this region. According to this feature, the studied area can be divided, first of all, into two large sections, the border between which runs approximately along the meridian of the underwater Pervenets Rise $\left(132^{\circ} 30 /\right)$. To the east of this boundary is the deepest part of the basin with a maximum protrusion of 


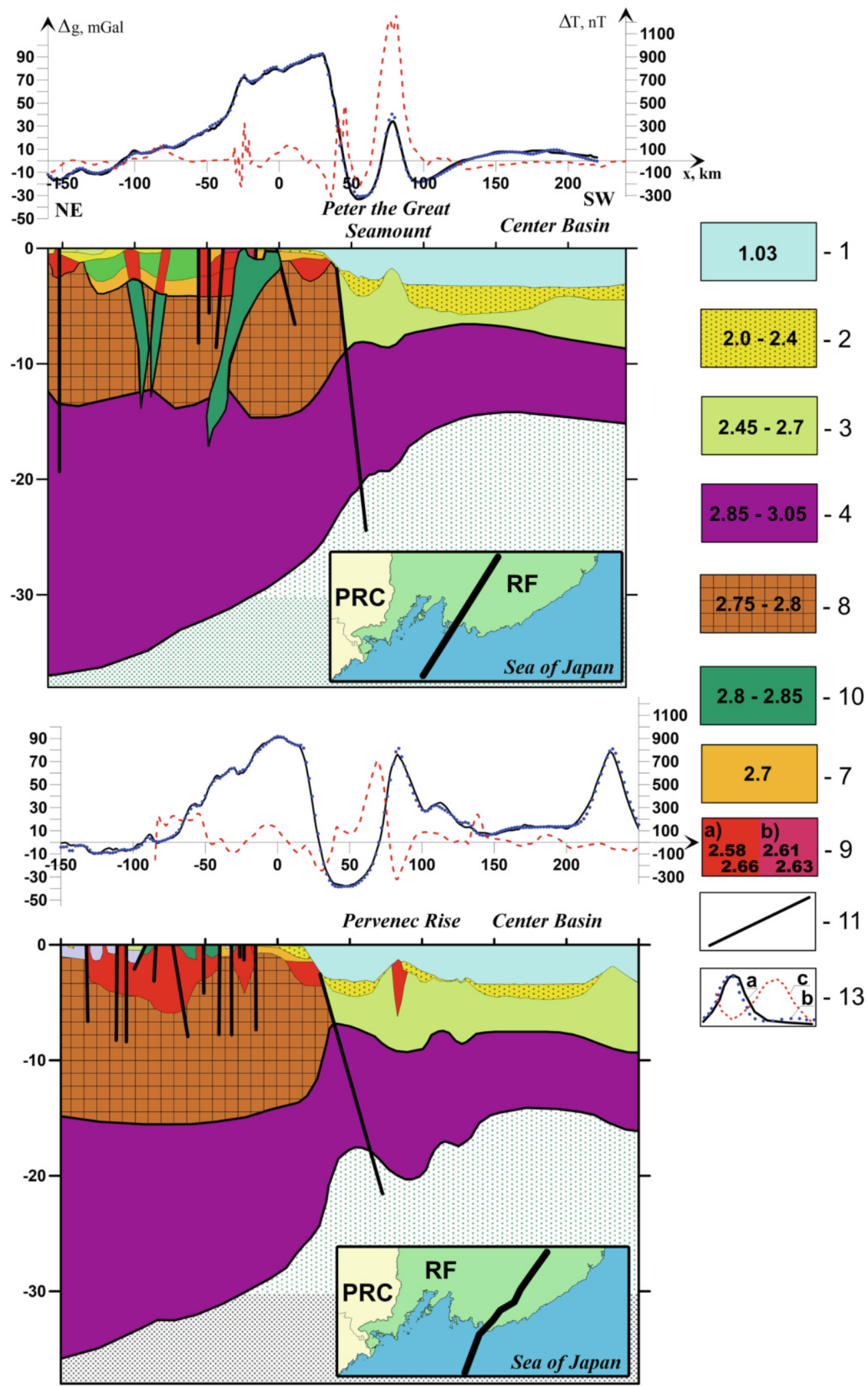

Fig. 3 Structural-density models of the earth' crust in the transition zone from the mainland to the Sea of Japan. 1 - water column; 2 sedimentary layer; 3 - volcanic sedimentary layer; 4 - "basalt" layer; 5 - crystalline basement, 6 - gabbroids, 7 - pre-Mesozoic sedimentary formations, 8 - granites, 9 - faults, 10 - a) observed gravitational field, b) calculated gravitational field, c) magnetic field. Numbers - densities $\left(\mathrm{g} / \mathrm{cm}^{3}\right)$ of rocks. The inset shows the position of the profiles. RF Russian Federation, PRC - People's Republic of China 


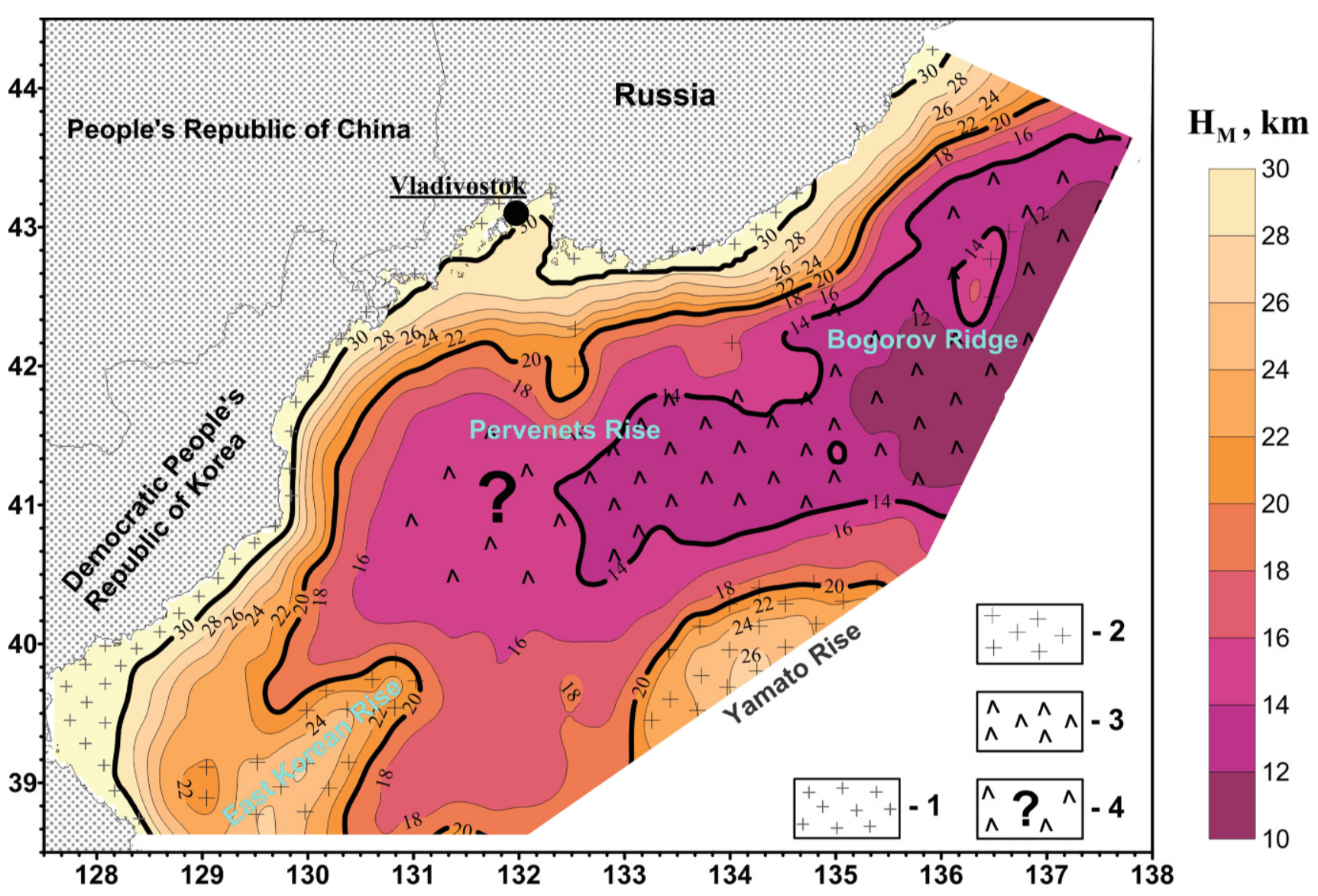

Fig. 4 The map of the Moho discontinuity isodepths (kilometers below the sea level) and the types of crust beneath the north-western part Sea

2 - reduced continental crust; 3 - oceanic crust; 4 - presumable oceanic crust with the thickened sedimentary cover (suboceanic?)

the Mohorovičić discontinuity, the depth of which from the day surface varies from $14 \mathrm{~km}$ in the west to $12 \mathrm{~km}$ or less in the east. Without a water layer, the crust thickness here is $10.5-8.5 \mathrm{~km}$, respectively, which is in good agreement with the results of seismic studies (Hirata et al. 1992). The Earth crust here is of the oceanic type. This area has a wedge-shaped east-north-east strike, complicated by local thickening of the crust up to $16-20 \mathrm{~km}$ within the underwater elevations.

The western half of the basin differs significantly from the previous one by the great depths of the Mohorovičić discontinuity $(16-18 \mathrm{~km})$ and a different pattern of its relief. The central place here is occupied by a vast, laid out section of the western end of the basin of almost isometric shape, within which the depth of Moho is $15-16 \mathrm{~km}$. Two "apophyses" with a relatively high position of Moho, separated by an East Korean Rise, depart from this section in the south-west and south directions. The thickness of the consolidated crust here is $13-15 \mathrm{~km}$, which allows us to attribute it to the suboceanic type.

The thickness of the crust within large submarine hills reaches $26 \mathrm{~km}$, which is characteristic of the Earth's crust of a subcontinental type. The transition from the deepsea basin to the continent is accompanied by the intense lowering of Moho to depths of $30 \mathrm{~km}$ and more, which corresponds to the minimum thickness of the continentaltype crust.

\section{Conclusion}

For more than half a century, Russian and foreign researchers have been studying the geological structure and natural fields of the Earth in the waters of the Sea of Japan. Scientists of the Pacific Oceanological Institute of the Far Eastern Branch of the Russian Academy of Sciences made the most complete contribution to this process, in the waters of the economic zone of Russia (formerly the USSR). Gravimetric studies, as one of the deepest geophysical methods, made it possible to determine the thickness and types of the earth's crust, study its internal substantial-density structure, separate blocks and trace tectonic faults. The integration of gravimetry with other geophysical methods, especially with deep seismic sounding, significantly improved the accuracy 
of these studies and reduce the ambiguity of the result. Thus, we can say that the first stage of the study of the gravitational field of the Central Basin of the Sea of Japan has been completed. In the future, it is necessary to focus on a detailed study of individual morphostructures, the implementation of near sea bottom gravimetric observations and the gravity field's gradients calculation, which, in combination with other geophysical methods, will provide new information on the structure and substantial composition of the earth's crust in the region.

The fundamental study and interpretation of the gravitational field in the waters of the Tatar Strait, in the northern part of the Sea of Japan, has just begun. The four expeditions carried out, unfortunately, did not allow us to characterize the gravitational field of this morphological structure with the required detail, especially in the area of transition from the Central Basin of the Sea of Japan to the southern part of the Tatar Strait. The authors hope that research in this area will be continued, including in cooperation with Japanese colleagues.

Acknowledgments The expeditionary work of 2017-2019 was carried out with the financial support of the Ministry of Education and Science of the Russian Federation, within the framework of the State Assignment of the POI FEB RAS: Subject 0271-2019-0002 (AAAA-A17-117030110032-3), Subject 0271-2019-0006 (AAAAA17-117030110035-4), as well as the Priority Program of the Far East Branch of the Russian Academy of Sciences "Far East" (grant 18-1-010).

\section{References}

Belousov VV, Pavlenkova NI (1985) Types of the Earth's crust. Geotectonics 1:3-14

Belousov IM, Levitskaya ZN, Panteleev VL, Stroyev PA (1973) Geophysical surveys on the Yamato Upland. Results of geological and geophysical surveys in the 42nd cruise of the R / V Vityaz. M: "Science", Ocean Res 23:69-79

Bryansky LI (1991) Density structure of the crust and upper mantle of the central part of the Asian margin: problems and results of regional gravity modeling. Pac Geol 5:39-48

Hirata N, Karp BY, Yamaguchi T, Kanazawa T, Suyehiro K, Kasahara J, Shiobara M, Shinohara M, Kinoshita H (1992) Oceanic crust in the Japan sea by the 1990 Japan - USSR expedition. Geophys Res Lett 19(20):2027-2030. https://doi.org/10.1029/92GL02094

Krasovsky SS (1981) Reflection of the dynamics of the continental crust in a gravitational field. NaukovaDumka, Kiev

Prokudin VG, Sedin VT, Valitov MG, Medvedev SN (2018) The Central Basin of the Sea of Japan: a history of study and tectonics. Bull KRASEC 4(40):1-22. https://doi.org/10.31431/1816-5524-2018-440-82-104

Stroev PA, Kovylin VM (1973) Results of geophysical measurements in the 47th cruise of the R / V Vityaz. Geophys Bull 25:57-61

Stroev PA, Panteleev VL, Levitskaya ZN, Chesnokova TS (2007) Underwater expeditions of the GAIS. From the history of science. University Book House (KHU), Moscow

Su Datsuan (1982) Interpretation of gravity measurements in the middle and northern parts of the South China Sea: translate with a Chinese. Oil Geophys Prospect 4:45-56

Tomoda Y (1973) Maps of free-air and Bouguer gravity anomalies in and around Japan. University of Tokyo Press

Tomoda Y, Fujimoto H (1981) Gravity anomalies in the Northwestern Pacific and their geophysical interpretation. Proc Japan Acad Ser B Phys Biol Sci 57(10):359-361

Open Access This chapter is licensed under the terms of the Creative Commons Attribution 4.0 International License (http://creativecommons.org/ licenses/by/4.0/), which permits use, sharing, adaptation, distribution and reproduction in any medium or format, as long as you give appropriate credit to the original author(s) and the source, provide a link to the Creative Commons license and indicate if changes were made.

The images or other third party material in this chapter are included in the chapter's Creative Commons license, unless indicated otherwise in a credit line to the material. If material is not included in the chapter's Creative Commons license and your intended use is not permitted by statutory regulation or exceeds the permitted use, you will need to obtain permission directly from the copyright holder.

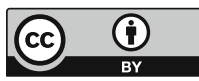

